\title{
Unique conference to focus on FtP
}

The first ever UK medico-legal conference to focus on the Fitness to practise hearing process will take place in London on 20 March 2020.

The speaker list brings together for the first time experts in the world of regulatory law and healthcare who will share their experiences of the fitness to practise or tribunal hearing process. The conference will be headlined by defence solicitor Simon Eastwood, who has represented several high-profile medics including Team Sky doctor Richard Freeman and former Chelsea football club doctor Eva Carneiro. Simon will talk about his work in supporting doctors and dentists through an incredibly difficult personal and professional time as well taking an in-depth look at the legal processes involved.

Conference presenter Martin Murray said: 'It is commonly accepted that regulation in its current form continues to be a work in progress. Our aim is to explore some of the myths and mysteries associated with fitness to practise hearings. By bringing together some of the country's most respected experts, we hope to provide health care professionals with a knowledge bank that may be invaluable should they ever be unfortunate enough to receive a regulatory complaint in the future.'

The conference is recommended for any doctor, dentist, advisor, regulator or lawyer with an interest in medico-legal matters. Places can be reserved at: https://www.eventbrite.com/e/ preparing-for-gdcgmc-hearing-the-inaugural-uk-conferencetickets-85473434343.

Further information can be obtained from the Conference sponsors at hello@factuality.co.uk.

\section{New President for BASCD}

Maria Morgan, Senior Lecturer in Dental Public Health at Cardiff University and Hon Specialist in Public Health (Dental) at Public Health Wales, becomes President of the British Association for the Study of Community Dentistry (BASCD) in April this year.

Mrs Morgan, who has worked in dental public health in Wales for over 20 years, leading the work of the Welsh Oral Health Information Unit - overseeing the national epidemiology programme, monitoring Designed to Smile and Gwen Am Byth, to name a few roles - is the first non-clinical public health specialist to be nominated as President of BASCD.

Mrs Morgan is also registered as a specialist with the UK Public Health Register (UKPHR) and a fellow of the Faculty of Public Health and during her presidency she hopes that there will be closer collaboration between these organisations and BASCD.

The theme for the \#BASCD2020 conferences is Addressing Inequalities, Celebrating Improvement and considers the evidence on how best to further improve oral health of vulnerable groups. The Spring conference places the spotlight on children, whilst the Autumn conference centres on vulnerable older adults.

Mrs Morgan said: 'These conferences reflect much of my career in dental public health and celebrate the benefits of the reality, not the rhetoric, of multi-agency working to affect the wider determinants of health - after all we are stronger together.'

Maria's presidential conference, scheduled to take place on the 2-3 April 2020 in Cardiff's City Hall, will mark the success of Wales's flagship 'Designed to Smile' programme, as well as initiatives operating in the rest of the United Kingdom. It will also consider best practice to further improve children's oral health. For further information visit http://www.bascd.org/ conferences-and-events/.

\section{Photo story}

1980s film star E.T. has embarked on a whistle-stop tour of the Clyde Munro dental group in Scotland to help put patients' nerves at ease.

Fitted in custom-made scrubs, E.T. has plans to visit more than 30 practices from Inverkip to Inverness, and patients who catch a glimpse of him are being encouraged to share their sightings on social media (\#ETonTour).

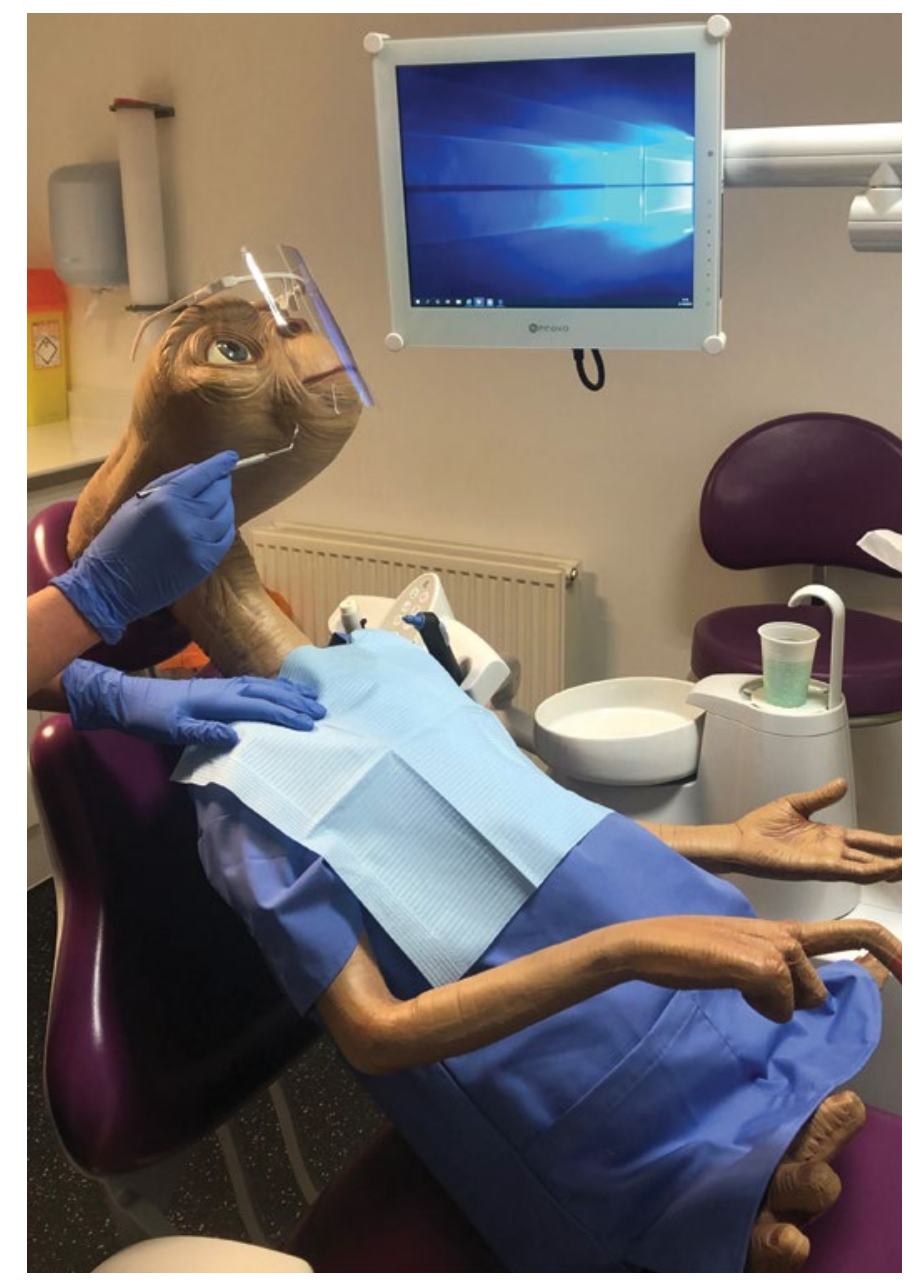

